\title{
Nuevas Perspectivas Sobre Violencia Social ${ }^{1}$ \\ por Michel Maffesoli ${ }^{2}$
}

V oy a intentar compartir algunas ideas sobre este tema inmenso que es la violencia. Esto es semejante a aquellos grandes temas antropológicos que tienen relación con el amor, la muerte y que constituyen (en el verdadero sentido filosófico del término) una preocupación, y frente a los cuales también es necesario tomar distancia intelectual. Lo que estoy queriendo decir con esto es que lo que nos toca más de cerca necesita, en verdad, colocarlo a una cierta distancia, en particular para nosotros, intelectuales, que estamos confrontados a estas emociones colectivas, y que al mismo tiempo tenemos que reflexionar sobre ellas.

Hay otro aspecto que también hay que considerar sobre la violencia social, y en este campo más que en muchos otros, es el no tener una actitud represiva, judicativa o normativa. No nos corresponde, a partir de un juicio de valores, decir si tal cosa es buena o tal otra es mala. Hace mucho tiempo que estoy trabajando este tema de la violencia y pienso que hay que aplicar esa vieja regla weberiana de la neutralidad axiológica y no entrar en una lógica del deber ser. Debemos contentarnos en un primer momento con decir lo que es, y a partir de las convicciones poder actuar. Entonces, esta neutralidad axiológica es aún más difícil, no sé aquí, pero en Francia hay una especie de exageración mediática sobre

1 Conferencia dictada en la Universidad Diego Portales de Santiago de Chile, el 31 de Octubre del 2001. La traducción es de Justino Gómez de Benito, Director departamento de Sociología, U.C.Cardenal Raúl Silva Henríquez.

2 Sociólogo francés. Profesor de la Universidad de la Sorbonne de París. Director del Centro de Estudios de lo actual y lo cotidiano y del Centro de Estudios sobre lo imaginario. Es además Presidente del Instituto Internacional de Sociología. Su producción intelectual ha sido muy relevante en la comprensión de formas emergentes de sociabilidad y en el desarrollo de enfoques innovadores en Ciencias Sociales. 
fenómenos que, finalmente no son tan importantes en lo concerniente a la violencia. También ahí está ubicado un problema teórico importante: ¿por qué algunos fenómenos de delincuencia o de violencia, de cualquier tipo, son extrapolados como constituyéndose en la verdadera preocupación social?

Encontramos que, históricamente a partir de trabajos muy serios que han demostrado que en términos de escala relativa a la población hay menos violencia en la actualidad que en la edad media. Si se toma el ejemplo Parisino, hay más seguridad en la ciudad contemporánea que al final del siglo XIX o a principios del XX. Hay un desfase curioso entre un hecho, una realidad y la interpretación que se hace de él. Por lo cual, insisto, estamos ante un problema teórico. Nos hemos acostumbrados a una "ideología del riesgo cero" de una segurización generalizada. Y a partir de ahí, hay una suerte de incapacidad de integrar una pequeña disrupción en la concepción generalizada de esta segurización. No voy a extenderme en eso, pero hay un problema simple en el fondo. Es esta constatación empírica que me lleva a colocar el problema en perspectiva.

Es mi intención en un primer momento mostrar como lo que se llama violencia en sus varias modalidades, es de hecho una modalidad estructural de lo que es el individuo y de lo que es la sociedad en su conjunto. Si tomo de nuevo aquí el concepto durkhemiano de anomía, que aunque es un tanto difícil de traducir, déjenme traducirle como algo fuera de la ley, al margen de la ley, el lado de la ley, por encima de la ley... poco importa. Durkheim muestra muy bien que no puede existir ley (nomos) si no existe algo que la va a fecundar. Y es en este punto que él desarrolla su teoría sobre la anomía. De vez en cuando, en otros textos vuelven a tomar ideas semejantes poniendo énfasis sobre la efervescencia, para mostrar una suerte de vínculo estructural que va a existir entre orden y desorden. Digo bien un vínculo estructural. No lo hace porque su posición es estricta y simplemente sociológica, sino porque piensa que este vínculo estructural se va a encontrar también en lo que se puede llamar la estructuración individual. No lo voy a desarrollar con detalle, pero en el fondo somos lo que somos si existe una suerte de fuerza interna que traduce el caos que cada uno tiene adentro. Esta sería mi tesis. 
Individualmente, o colectivamente existe una violencia fundadora. Si tenemos presente en la mente la existencia de la violencia fundadora, podremos entonces relativizarla, utilizar la violencia, servirse de ella. Es a aparte de esto que podremos "homeopatizar" esta violencia. No se trata entonces de tener una actitud judicativa, sino una sabiduría empírica. En el fondo cuando uno mira las historias humanas desde hace dos mil años, se nota que la sociedad es equilibrada, y que se han construido a partir de un equilibrio, de una armonía activa, elegante, integradora, de lo que constituye el individuo, y de lo que constituye la sociedad. Voy a dar un ejemplo antropológico, y otro de tipo mitológico. El ejemplo antropológico lo voy a tomar de los ejemplos de Durkheim en su libro "Las formas elementales de la vida religiosa". En este gran libro muestra como a partir de la religión, cuales son los elementos fundadores del vínculo social. Hay en este libro dos o tres capítulos interesantes que son un análisis de hechos específicos de unas tribus australianas. Son hechos que se pueden vincular al carnaval u otros hechos o momentos festivos. Es el momento festivo, con toda la efervescencia que sé hay dentro de él, y también toda la violencia que hay dentro de lo festivo. La tesis de Durkheim y que vamos a encontrar también entre historiadores como Luis Ingar o en filósofos como Callua, que demuestran todos la necesidad del "homo ludens", el hombre que juega. Como descripción simple, las tribus están extendida en todo el territorio, viven sus vidas cotidianas y regularmente, de manera relativamente misteriosa siente la necesidad de juntarse. La expresión durkhemiana es interesante. Dice que estas tribus se colocan en un estado de congregación. Se juntan. Hay entonces una larga descripción hecha por Durkheim que pone el énfasis sobre la violencia ritualizada, los excesos de todo orden, alucinógenos, comidas, promiscuidad sexual, etc. Hay todo un desarrollo muy interesante porque Durkheim era un pequeño burgués nacionalista y un poco socializante. Hace él una descripción, que claramente son contrarias a sus convicciones morales. Describe valores que son "valores de exceso", aun se puede hablar de valores inmorales. En este momento tiene una fórmula que le parece muy rica. En este momento, dice, la comunidad conforta el sentimiento que tiene de ella misma. Es algo extraordinaria esta frase. La comunidad se hace comunidad, a partir de elementos que, en principio, están fuera o en contra de la comunidad: en la efervescencia, en el exceso, en la inmoralidad. Existe todo un desarrollo de Durkheim 
a partir de esta situación, pero se da ahí una especie de fecundación de lo que es anómico. Yo he hecho un comentario de este libro, mostrando que en el desarrollo durkhemiano, lo anómico de hoy será lo canónico del mañana. Digo bien, lo anómico, lo que está fuera de la ley hoy, va a ser mañana el valor del mañana. Podemos divertirnos y tratar de buscar elementos de hace cien años viendo como en todos los campos, lo que era anómico se ha transformado en la referencia. Los poetas malditos, en el siglo XIX, los músicos malditos, los teóricos malditos, los modos de vida malditos. Si lo dijera a la manera de Baudelaire, las "flores del mal”, han pasado a ser, de alguna manera, el canon, la referencia en todos los dominios de la vida social.

Ven Uds., y vuelvo a mi idea, que es, para nosotros intelectuales, una especie de forma de prudencia, de sabiduría, de estar atentos a lo anómico de hoy. Si soy aún más prudente, no diré que todo (y en estos momentos me pongo más prudente) lo anómico vaya a llegar ser canónico, pero lo que es cierto, es que lo canónico siempre saldrá de lo anómico. Hay un pequeño matiz casi cuantitativo. Pero, al contrario, estructuralmente, (y eso que no me gustan las leyes sociales), ahí hay una ley social. Y lo digo desde el texto de Durkheim, es necesario mirar la literatura o cualquier dominio de creación, para darse cuenta que existe ese mecanismo. Y digo bien esta palabra mecanismo en el sentido simple del término. Este es el ejemplo antropológico para que nos ayude a reflexionar.

Ahora voy a dar dos o tres ejemplos, no sé si puedo decir mitológicos. Y lo que voy a decir es del orden de la vanalidad. Todos los grandes sistemas de pensamiento o en todo caso en lo concerniente a nuestra tradición cultural. Yo pienso que podré extrapolar el objetivo. Si nos mantenemos en la tradición judeocristiana, vemos que en el fondo siempre hay algo que remite a una violencia fundadora. En esta gran tradición que es la cristiana por ejemplo, el signo de la cruz, es una marca de violencia. No se piensa en ello siempre, pero los que tienen esta condición cristiana llevan en su pecho el signo de la violencia extrema, el de la crucifixión.

La gran mitología freudiana, no importa lo que se piense, hace reposar el conjunto social sobre la muerte del padre. En Totem y Tabú, se muestra muy bien como se produce la muerte del macho dominante. En la gran 
idea freudiana es a partir de la muerte del padre como se va a cimentar la sociedad. Él insiste, cimentar la sociedad.

Y el tercer discurso mitológico marxista, el punto nodal del discurso hegeliano-marxista es la famosa dialéctica del amo y del esclavo. ¿Pero qué es esta dialéctica del amo y del esclavo?. Si el esclavo sabe enfrentar la muerte, sabe que va a ganar la vida. He aquí el nudo que va a explicar después de la lucha de clases. Es la capacidad de enfrentar y de integrar la muerte. Estos son los tres ejemplos que yo digo mitológicos. Y cuando lo digo es porque en el fondo va a servir de base al estar juntos. De alguna manera es una especie de anamnesis del mal, de anamnesis de la violencia y de la muerte. Esto muestra bien que no hay vida sino a través de la integración de la violencia. Vida en la idea de vitalidad, vitalismo, esta capacidad de saber integrar siempre su contrario. Este es el nudo fundamental de la teoría de la violencia. Y si vuelvo a la idea anterior, de manera más o menos consciente, pero la mayor parte de las veces, inconsciente, (en el sentido del inconsciente colectivo), pienso que existe en la base de toda estructuración esta especie de equilibrio conflictual. Diciéndolo de una manera más exquisita, la "coincidentia opositorum" (la coincidencia de las cosas contrarias) lo que hace sustentar un equilibrio sobre la coincidencia de las cosas contrarias. Me parece que es este equilibrio el que en un momento dado se rompe. Y que se rompe en el apogeo de la modernidad. Es decir, en el momento en el que se quiere hacer del bien un valor absoluto. Ese es el verdadero peligro: el bien, lo bueno. Una vez más estoy diciendo cosas sencillas, de sentido común. Hay un proverbio que dice que "el infierno está pavimentado de buenas intenciones". Esa es verdadera sabiduría popular. Solamente se busca hacer el bien, pero es una vez más olvidar el animal al interior del ser humano. Hay una frase que me parece una verdaderamente ruptura, corte o herida. No recuerdo si era Robespierre o Saint-Juste quien al hablar de la Revolución Francesa, decía que la felicidad es una idea nueva en el mundo. Es una pretensión extraordinaria. Quiero decir que fue en nombre de la felicidad que cortó tal cantidad de cabezas. Fue "el terror". Lo interesante es que la extrapolación de un valor va a llegar a exactamente lo contrario. Vean cual es mi tesis. Si logro integrar el mal, si me arreglo con él, si lo niego, el mal se venga. En grandes rasgos es lo que me parece la característica de la modernidad. El gran mito progresista 
consiste, diciéndolo de una manera un poco cortante, en querer expulsar la muerte, negarla en nombre de la felicidad que se va a proclamar, que se va a imponer y que se va a constituir en valor único.

Vemos entonces que a lo largo del siglo XIX ¿qué se va a imponer progresivamente?. Es una asepsis social. Asepcia social como ideal (porque hay una asepcia social es por lo que va a ver una cantidad de enfermedades no tolerables). En el fondo no hay nada más peligroso que los hospitales porque se entra con una enfermedad y se puede morir por otra. La sociedad entonces es como un gran hospital. Hemos querido aseptisar al máximo y entonces el cuerpo no es capaz de resistir la agresión externa. Y ese es el verdadero problema. Un cuerpo individual o un cuerpo social en el que se han suprimido las defensas internas y externas, es la asepcia. Por eso la verdadera violencia esta ahí, esa es la violencia que he llamado violencia totalitaria. Si yo puedo permitirme les remito al libro que escribí, "La Violencia Totalitaria”, y que está traducido al español. Tengo que decir que es un libro muy complicado y difícil de leer, pero muy interesante. En ese libro está toda mi tesis: el peligro del riesgo cero, que es lo propio del ideal moderno, el peligro de la segurización total de la existencia. Porque es partir de esta violencia totalitaria (estoy diciendo que se trata de la violencia de la felicidad) que yo, que sé lo que es la felicidad, yo que tengo el poder te ruego someterte. Es esta también la gran perspectiva pedagógica. Considero por otro lado que no es una provocación sencilla, y que no es nada extraño que esta pedagogía termine en pedofilia. En el fondo está la misma facultad de poder violar al otro. Yo sé que la palabra es grosera pero esta es la realidad. No se olviden que, al menos en Francia, donde hay mayor cantidad de pedofilia es en el campo de la educación. Hay aquí mucho más que algo anecdótico. Se trata del gran fantasma del poder. Es esa la verdadera violencia totalitaria, que es institucional y que es violencia de los padres. Es la violencia de Dios Padre: "yo sé lo que es bueno para ti”.

Es a partir de esto, y es el tercer punto, de donde, y casi legítimamente se expresa la vuelta de lo reprimido, aquello a lo cual no he dado ninguna expresión. Estoy diciendo estructura de base. Si no puede expresarse 
como se exprime el jugo de una naranja se transforma en algo perverso, dañino. Pero ¿qué es la perversión?. En latín es "per-vía”, lo que toma un camino torcido un camino lateral. Si no puedo expresarme en forma natural buscaré algún desvío. En ese momento la violencia natural se transforma en sanguinaria. Y lo que viene a ser propio de la sociedad contemporánea, en términos generales de estas sociedades aseptizadas, elaboradas a partir de la ideología de la felicidad se producirán una multiplicidad y explosiones de las locuras mortales, violencias sanguinarias, etc. Se puede apreciar que en el seno de las sociedades de riesgo cero, de repente alguien va a salir con un fusil a disparar contra la gente. Los EEUU en este sentido son un caso interesante. Viene a ser como un laboratorio para mí. Vemos entonces en forma muy precisa como habiendo querido eliminar esta violencia fundadora, tenemos dificultad para eliminar la violencia sanguinaria. No se puede ni erradicarla, ni negarla. No hay solución. Siempre habrá problemas.

Ese es el equilibrio conflictivo, lo que he llamado en el fondo la homeopatización, que es acorde con la preocupación de los filósofos de la Edad Media, que poseían una bonita expresión sobre la violencia. En latín decían el "bon usus", el buen uso de. Todo lo que puedo decir sobre el tema de la violencia es esto. Ni erradicarla totalmente, ni denigrarla por lo que es, sino que en referencia a una óptica antropológica o mitológica, o en referencia a la sabiduría popular, llegar a tener este buen uso. No hay solución. Siempre hay problemas, problemas que se vuelven a presentar regularmente. En términos de Platón es una sabiduría demoníaca, el saber integrar los sentidos, el animal en lo humano. En esta perspectiva de reflexión hay que insistir en la sabiduría demoníaca. Yo soy particularmente un partidario de esta sabiduría demoníaca. Simplemente, encontrar una vez más lo medios para integrar los sentidos de este animal dentro de lo humano, poniendo el acento en una proximidad semántica detectando el "humus en lo humano". Lo humano está empapado de este barro, de este humus. Y siguiendo con esta proximidad semántica, tener la humildad de reconocer el humus en lo humano. Y esto, en contra de lo que es la gran paranoia del poder, del poder político o del poder simbólico que es paranoico. 
Sabemos lo que es la paranoia, el poder sorprendente, que está por encima del bien y del mal, que está sobre lo verdadero y lo falso. En el fondo es esta especie de gran paranoia que, no olvidemos, es primero una paranoia divina. Es Baudelaire el que habla de Dios como el gran paranoico. Y entonces el intelectual es un pequeño paranoico de servicios: el que sabe. Entonces la humildad del humus es una vez más puntualmente, golpe a golpe, es esta capacidad de integrar la violencia. Es lo que se encuentra en otras sabidurías humanas, saber hacer de la debilidad una fortaleza. Grosso-modo es esa la táctica diferente. O bien yo niego y combato, o al contrario, integro. Me parece que en esta integración de la debilidad hay algo que puede dar una gran fuerza individual y social. Dejo esto a su meditación.

\section{Diálogo con el público}

Público: "Se ha hecho una investigación sobre las barras bravas del fútbol, no desde el estadio, sino desde la perspectiva territorial, en su lugar, la población El Castillo, en La Pintana. Hay dos grandes barras con graves enfrentamientos y muertos. Quiero destacar el hecho de que nuestra sociedad se plantea siempre en la erradicación del desorden. Pero algo que nosotros hemos encontrado en la investigación es que la manera en que la violencia representa a estos jóvenes es una manera de construir un orden que se asegura sólo desde dentro. La violencia mirada desde afuera genera violencia, pero mirado desde dentro, desde la lógica de los actores no cualquiera enfrenta a cualquiera, no cualquiera con cualquier arma, en cualquier lugar ni en cualquier momento. El enfrentamiento tiene un significado preciso. Es una manera de construir un orden, un orden precario. La violencia constituye un principio de construcción del orden. Una segunda inquietud tiene que ver con el nomadismo, se dice que estamos pasando de una época de identidad a otra de identificación, de convivir con distintos momentos de construcción de identidad. En la figura de los barristas hemos encontrado demandas de ser sí mismos , una identidad que se define en oposición a otros tipos de luchas, por ejemplo estar los 7 días de la semana con la camiseta, u ocupar el mismo lugar en el estadio, en el mismo lugar en la población, ser el mismo en el mismo sitio o lugar". 
M. Maffesoli: Sobre la primera cuestión, estoy de acuerdo con usted en ese desborde de ejemplos, de que puede existir ese lado constructivo del desorden. El problema anterior de lo que estamos diciendo, y que hace difícil la apreciación o el juicio social, es que nuestro modelo analítico-esencial es el universalismo. Hay un valor o un conjunto de valores. A partir de esto hay dificultad para apreciar prácticas de ese grupo de jóvenes (de estas tribus) que no corresponden al valor universal y que en relación a los valores universales son anómicos, pero que son constructivos para el grupo mismo. Yo propuse la fórmula siguiente para describir las prácticas de estos grupos que llamo "inmoralismo ético" siendo preciso con el término: inmoral en relación a la idea de moral, porque la moral es universal, es ley general aplicable en todo tiempo y lugar. Mientras que la ética (ethos, en griego) es el cemento lo que vincula al otro. La mafia puede ser inmoral pero es ética. Para mí un pequeño grupo de fútbol o de delincuentes, puede ser inmoral y ético. Esa es mi respuesta. Estar atentos a estas inmoralidades éticas o a este inmoralismo ético porque de hecho, cada vez más vamos a estar confrontados a estos inmoralismos éticos. No adelantamos nada con tener una actitud moral frente a esto. Hay que estudiar como estos inmoralismos se van a ajustar unos con otros. La proposición que yo hago es la idea de la "ceoenestesia". Este término viene semánticamente de la idea de "aistesis", sensación y derivando de koinos que significa todo y de "kine" que es movimiento.

Los médicos hablan de la cenestesia corporal, hablan de esta especie de sensación del ajuste del todo y del movimiento, de lo fluido, la sangre, los humores. Por eso cuando uno se siente bien en su piel es que tenemos este tipo de ajustes de los órganos unos en relación con otros y de lo sólido en relación a lo fluido. Los psicólogos que utilizan este término de cenestesia lo hacen cuando los niños aprenden a caminar. Cuando los niños son atraídos por algo que se mueve o por algo brillante, van, se caen, se golpean con algún un mueble etc.. En un momento dado el niño va a tener la aitesis, la sensación de movimiento y del espacio. Por eso hablo de una cenestesia corporal y en relación con esto a una cenestesia social. De la misma manera que en el cuerpo social, es esta especie de ajuste progresivo de las tribus, unas en relación con las otras. Se trata del ajuste a posteriori. No es el universalismo. Grosso modo es 
lo que se trata de hacer aquí. Es un ajuste a posteriori de las tribus, de unas respecto a otras. El paso que estamos dando, la transición entre la homogeneización del mundo y la heterogenización del mundo, para mí modernidad-posmodernidad, va a ser un período cruel. La sangre va a correr. Porque evidentemente estamos acostumbrados a un modelo homogéneo y tenemos dificultad para entender los ajustes de unos grupos con otros. Es una verdadera iniciación. Y quien dice iniciación dice prueba, muerte simbólica. Estamos en un período de pasaje. Yo encuentro que este tema de las barras es apasionante. Son estos grupos los que se van a desarrollar. Son las tribus: tribus deportivas, sexuales, religiosas.

En cuanto a la segunda cuestión yo mantengo la idea de las identificaciones múltiples. Reconozco que estamos en un período en que predomina la paradoja. En un momento dado puede existir una identidad fuerte. En un momento dado me puedo poner la camiseta de un club como una forma de imitación. Si hablo a la manera de Miguel Tarde (sociólogo del siglo XIX que escribió el libro "Las leyes de la Imitación") y su ley de la imitación. Aconsejo leer a Tarde, como a Nietzsche, por ser un autor no contemporáneo, pero particularmente pertinente y contemporáneo para nosotros, sobre todo en este tema de la ley de la imitación. Esta es mi respuesta, puede haber una identidad fusional que va a funcionar sobre las imitaciones. Pero son identidades fuertes en un momento dado pero al mismo tiempo, mañana, o en otro momento, se puede presentar otra identidad. Esto es la identificación. A esto lo llamo las "sinceridades sucesivas". En un momento (T1) existe una fuerte adhesión al grupo. Y en otro momento (T2) hay otras identificaciones a otros grupos. Hice un pequeño estudio con diferentes grupos de jóvenes parisinos en los que veíamos imitaciones en la vestimenta, según la tribu en la que se estaba en un momento dado. Y que variaba según las tribus. Y esta especie de ley de la imitación llegaba tan lejos que incluso la ropa interior era semejante. Los varones y las mujeres utilizaban los mismos colores de ropa interior, y que variaba según la pertenencia a otras tribus. Se trata entonces de identidades fusionales, pero momentáneas. Para traducir estas identidades momentáneas utilizo el término de identificaciones múltiples. Pero hay una paradoja, lo reconozco. 
Público: Sobre el tema de lo mediático, los medios de comunicación y el mostrar imagen de violencia como si fueran los temas más importantes, la pregunta es la siguiente: ¿hasta que punto esta violencia en los medios de comunicación va a reemplazar la ritualización de la violencia, ejercido desde una cultura de poder?. Entendiendo que los medios de comunicación están situados en una lógica de poder que es retomada por debajo por una violencia autosacrificatoria, residual que instala un ritual de violencia.

M. Maffesoli: Al comenzar mis palabras tuve una posición un poco rápida. Es necesario poner algunos matices. Pienso que de alguna manera puede haber en la puesta en escena mediática algo que pertenece al orden la ritualización de la violencia. Lo que quiero decir es la reutilización política de esta presentación mediática. Hablo del caso de Francia pero la izquierda y la derecha, confundidas, mezcladas, utilizan el miedo de la violencia a partir de ejemplos mediáticos. No estamos hablando de la extrema derecha. La izquierda en el poder también lo hace. Es el mismo miedo pequeño burgués. Por el contrario me parece importante lo que digo del uso de la reutilización política de esta presentación mediática.

En el fondo encuentro que la presentación mediática es muy interesante y juega, de hecho, el rol de ritual. Hay un concepto durkhemiano que me parece genial que son los "ritos piaculares". Hay todo un desarrollo de los ritos piaculares que hace Durkheim. Los ritos piaculares son los ritos del llanto. El autor muestra cómo es necesario a veces que una comunidad llore junta y que al llorar se consolida, se une: eso es parte de su ética. Hay una vinculación que se establece por esta práctica, el llanto de la tristeza. De ahí la necesidad de mirar la catástrofe, los temblores, los incendios, los noticiarios desde este punto de vista son la expresión de este rito piacular. Uno de estos ritos piaculares mundiales fue, por ejemplo, la muerte de aquella famosa princesa inglesa. Se trataba de una suerte de personaje, de "una imbécil", sin ninguna calidad humana, era "la imbécil perfecta". Ella muera en un accidente de automóvil y el mundo entero se pone a llorar. Es espléndido. Es la expresión de este rito piacular. Entienden ahora por qué he dicho tantas bondades de Lady Di, porque el objeto no es lo importante. Es ella en tanto símbolo, es 
un objeto símbolo que hace que a un momento dado haya un llanto que va a establecer vínculos, esto lo que se llama un efecto de estructura mas allá del objeto humano mismo. Es algo de este orden lo que se ve en las formas de violencia mediática. Se trata de la necesidad de poner en escena la muerte. Y la gran tontera que hacen los EEUU en los últimos días es no haber querido mostrar los muertos. Es una gran tontera, una gran imbecibilidad, porque no se puede hacer este rito piacular. Se ha querido esconder la muerte. El haber escondido estas dos torres es haber escondido la muerte y no haber hecho rito piaculiar. Esa es mi respuesta. Las diversas formas de violencia mediática: accidentes de autos, catástrofes, naturales atentados, se deben poner en escena para protegerse, para llorar y llorando purgarse. Es la gran idea aristotélica de la catarsis.

Público: Sobre el poder y la violencia intrafamiliar. Me gustaría saber cómo entiende este problema.¿ A qué se refiere cuando habla de poder?, ¿En qué medida puede haber una relación de abuso de poder?

M. Maffesoli: Sin ser un especialista sobre el tema, he dicho ya, hace un rato, algunos elementos que vuelven sobre el mismo tema, entre el poder familiar y el poder social ya que ambos se fundamentan en esta idea del poder de hacer el bien. Lo que he tratado de decir que es evidente en la violencia en el poder y en la violencia familiar, es que el gran fantasma del bien es siempre heterotélico, es decir que lleva a producir efectos perversos. Se trata de otro fin del que se persigue. Todas las extrapolaciones cualquiera que sean, para mí son heterotélicas y eso, en el fondo, en la tradición cultural nuestra, viene de la idea divina monoteísta. El monoteísmo no puede sino tener como final el infierno, porque es exactamente su contrario. Es esto lo que constituye nuestra tradición cultural. Otras tradiciones culturales ponen el acento sobre el politeísmo y esta es la gran perspectiva weberiana. Weber tiene una gran fórmula para hablar del politeísmo: "cuando los dioses se hacen la guerra los hombres están tranquilo". En el fondo, si uno traspone esta idea a los problemas que nos preocupan es que debido a que hay un modelo de Dios padre, por lo que hay violencia intrafamiliar. Están en la lógica del poder con el que media en este poder, el hombre macho. La gran estructura patriarcal es esta, y que es una forma de brutalidad. Mi 
maestro Gilbert Durand, gran antropólogo, ha reflexionado mucho en lo que se llama el "régimen diurno del imaginario". Muestra que nuestra tradición cultural reposa en este régimen diurno. Lo curioso es que hace resaltar las figuras de este régimen diurno. Y son todos objetos contundentes. Es la espada que corta entre el bien y el mal, entre lo verdadero y lo falso. Es la espada del juez, la espada de la razón. Es la punta del arado que penetra en la tierra. Es el falo erecto. Son estos los objetos contundentes de la brutalidad moderna. Todo estos objetos se utilizan en nombre del bien. Son un buen ejemplo: cortan, dividen, penetran. El falo, la espada, el arado, todos objetos cortantes, son símbolos de este régimen del poder que baja, un poder vertical. Él muestra también que hay otros modelos culturales, y que este autor llama el régimen nocturno de la imagen. La figura de este régimen nocturno es la copa, con la vagina, lo hondo. Y en esta copa que simboliza la femenización no hay objetos cortantes, contundentes. No existe la verticalidad, sino una forma de horizontalidad. En mis propios términos, y es mi respuesta, es lo que pasa actualmente. Dos tópicos diferentes, el tópico vertical, el patriarcado que ha caracterizado bien dos milenios de tradición judeocristiana y que se va a expresar en todos los términos de la vida social, incluida la familia, por supuesto. A esto se refiere lo que he escrito sobre la horizontalización del mundo, de un mundo más fraternal. La imagen de la tribu es eso, y corresponde al término de la familia mononuclear, como expresión de un esquema vertical del mundo. La horizontalidad distrae en la familia. El matriarcado es premoderno, pre-judeocristiano. Sólo el vientre es cielo, no el falo, sino la vagina. Se produce entonces una vaginización del sentido. 